\title{
Barley primary microRNA expression pattern is affected by soil water availability
}

\author{
Aleksandra Swida-Barteczka', Katarzyna Kruszka', Aleksandra Grabowska', Andrzej Pacak', \\ Artur Jarmolowski1, Marzena Kurowska², Iwona Szarejko² and Zofia Szweykowska-Kulinska ${ }^{1 \times}$ \\ 1Department of Gene Expression, Institute of Molecular Biology and Biotechnology, Faculty of Biology, Adam Mickiewicz University in Poznan, \\ Poznań, Poland; 'Department of Genetics, Faculty of Biology and Environmental Protection, University of Silesia, Katowice, Poland
}

\begin{abstract}
MicroRNAs are short molecules of 21-24 nt in length. They are present in all eukaryotic organisms and regulate gene expression by guiding posttranscriptional silencing of mRNAs. In plants, they are key players in signal transduction, growth and development, and in response to abiotic and biotic stresses. Barley (Hordeum vulgare) is an economically important monocotyledonous crop plant. Drought is the world's main cause of loss in cereal production. We have constructed a highthroughput Real-Time RT-qPCR platform for parallel determination of 159 barley primary microRNAs' levels. The platform was tested for two drought-and-rehydrationtreated barley genotypes (Rolap and Sebastian). We have determined changes in the expression of primary microRNAs responding to mild drought, severe drought, and rehydration. Based on the results obtained, we conclude that alteration in the primary microRNA expression is relative to the stress's intensity. Mild drought and rehydration mostly decrease the pri-miRNA levels in both of the tested genotypes. Severe drought mainly induces the primary microRNA expression. The main difference between the genotypes tested was a much-stronger induction of pri-miRNAs in Rolap encountering severe drought. The primary microRNAs respond dynamically to mild drought, severe drought, and rehydration treatments. We propose that some of the individual primiRNAs could be used as drought stress or rehydration markers. The usage of the platform in biotechnology is also postulated.
\end{abstract}

Key words: pri-miRNA, miRNA, drought, rehydration, barley genotypes

Received: 03 June, 2016; revised: 30 June, 2016; accepted: 20 July, 2016; available on-line: 21 October, 2016

\section{INTRODUCTION}

MicroRNAs (miRNAs) are a class of non-coding, single-stranded small RNA molecules, usually 21 nucleotides in length. They function as regulatory molecules, expressed in a particular developmental stage or in response to environmental changes. They control development, signal transduction, and protein degradation via negative regulation of gene expression. Many miRNAs are engaged in biological pathways leading to the adaptation of numerous biotic and abiotic stress factors (Khraiwesh et al., 2012; Kruszka et al., 2012; BarciszewskaPacak et al., 2015). These include miRNA-driven plant response to cold (Sunkar et al., 2004; Zhang et al., 2009), drought (Liu et al., 2008; Jian et al., 2010; Pieczynski et al., 2013), salt excess (Zhao et al., 2009), and oxidative stress induced by heavy-metal presence or nutrient limitation (Sunkar et al., 2006).

Most plant miRNAs are encoded by independent transcriptional units. MiRNA genes $(M I R)$ are often very long, and many of them possess introns (Szarzyńska et al., 2009, Kruszka et al., 2013, Kruszka et al., 2014; Alaba et al., 2015). The length of the MIR gene also varies within a single miRNA family, as was shown for ath-miRNA160a and ath-miRNA160b. ath-MIR160a is 2034 bp long and contains an intron of $1151 \mathrm{bp}$, whereas intronless ath-MIR160b is 378 bp long (Szarzyń-ska et al., 2009). Transcripts of the intron-containing MIR genes can be constitutively or alternatively spliced (Raczynska et al., 2010; Szarzynska et al., 2011; SzweykowskaKulinska et al., 2013). Additional differences within miRNA precursors result from the presence of several polyadenylation sites identified either in exons or introns. Also, alternative transcription start sites are present in the MIR genes, which was shown in Arabidopsis thaliana (Szarzyńska et al., 2009; Song et al., 2007). Some miRNA coding sequences are polycistronic. Such units code several miRNAs and occur in A. thatiana, Oryza sativa, and Physcomitrella patens (Lacombe et al., 2008; Talmor-Neiman et al., 2006; Zhang et al., 2010). While plant MIR genes are typically autonomous transcriptional units, there have been many examples of intragenic loci. MiRNAs can be imbedded within the introns of protein-coding genes or non-coding RNA genes (Rajagopalan et al., 2006; Brown et al., 2008; Szarzynska et al., 2011; Kruszka et al., 2013).

The MIR genes are transcribed by RNAPol II into primary transcript termed primary microRNA (pri-miRNA). Pri-miRNAs possess features of all RNAPol II products, like a 5' CAP and a 3' polyA tail (Lee et al., 2004). They contain a sequence folding into a hairpin structure called precursor miRNA (pre-miRNA). MiRNA, together with its partner miRNA*, are imbedded in the stem of pre-miRNA. Maturation of pri-miRNA into miRNA is a multistep enzymatic process, located in the nucleus. The main protein engaged in the microprocessing is DICER LIKE 1 (DCL1). DCL1 trims pri-miRNA hairpins and dices out miRNA/miRNA* duplexes. Pri-miRNA into miRNA processing efficiency and accuracy is facilitated by DAWDLE, SERRATE (SE), and HYPONASTIC LEAVES 1 (Yu et al., 2008; Yang et al., 2006; Kurihara et al., 2006; Szarzyńska et al., 2009). The proper processing of pri-miRNAs is further stimulated by the interaction of SE with the cap-binding complex (CBC) (Laubinger et al., 2008). The HUA ENHANCER 1 (HEN1) meth-

e-mail: zofszwey@amu.edu.p

Abbreviations: DH, doubled haploid; RNA-seq, RNA sequencing 
yltransferase 2'-O-methylates the 3' termini of the miRNA/miRNA* duplex and protects it from 3'-5' degradation or 3' uridylation (Yu et al., 2005; Yang et al., 2006). Next, HASTY (HST) drives the export of the miRNA/ miRNA* duplex to the cytoplasm (Park et al., 2005). The miRNA strand of the duplex is then loaded into the RNA-induced silencing complex (RISC), which is then guided to the target mRNA (Vaucheret et al., 2004). MiRNA* is generally degraded (Eamens et al., 2009).

MiRNAs regulate gene expression at the posttranscriptional level through mRNA degradation or inhibition of translation (Bartel, 2004; Carthew \& Sontheimer, 2009; Lee et al., 2002). The degree of complementarity between miRNA and mRNA defines the mechanism of miRNA action. mRNAs of nearly full complementarity to specific miRNAs are targeted for degradation. Such mRNAs are cleaved in the center of the miRNA/mRNA pairing region. The resulting mRNA fragments are degraded (Llave et al., 2002; Rogers \& Chen, 2013). Translation suppression without mRNA cleavage is observed when the miRNA/mRNA complementarity level is low. Such miRNA guides the RISC complex to target the 3' UTR of the translated mRNAs (Brodersen et al., 2008).

Arising water deficit in areas designated for crop-plant cultivation is a major cause of loss in world food production ( $\mathrm{Li}$ et al., 2009). Hence, drought is one of the world's major abiotic stress factors that lead to plant growth and development inhibition. Large areas in Poland are also coping with prolonged periods of drought (Szwed et al., 2010). This has escalated in the recent decades and poses a serious environmental and economic problem. Drought is defined as a disruption of intracellular balance of water caused by a predominance of transpiration over water uptake. Water depletion causes numerous alterations in plant physiology and biochemical processes. Inhibition of gas exchange and $\mathrm{CO}_{2}$ assimilation leads to a reduction in sugar biosynthesis. Drought-induced changes in nutrient distribution cause vegetative and eventually generative growth inhibition. Studies on the influence of drought on plants are essential for recognizing the plant rescue mechanisms.

Barley is a cereal of a great economic importance (http://www.fao.org). Its estimated world production is fourth among cereals, after wheat, rice, and maize. Barley production in Poland ranks third (after wheat and rye). It is commercially used for animal feed and human consumption, and it is the primary ingredient for beer production. Since miRNAs are considered key-regulators of gene expression at the post-transcriptional and translational levels, they are good candidates for studying the mechanisms of abiotic stress responses of crop plants. However, global mature miRNA-expression analysis requires time-consuming and expensive methods.

Despite barley's great economic importance, knowledge on its miRNAs is very limited. At this time, there are only 69 barley pre-miRNAs and 71 miRNAs deposited in the miRBase (Kozomara \& Griffiths-Jones, 2014). Next-generation sequencing of small RNAs provided information about barley mature miRNA sequences (Schreiber et al., 2011; Lv et al., 2012). Also, it has been reported that drought affects the expression profiles of many barley miRNAs, generally toward down-regulation (Hackenberg et al., 2015).

Using a previously designed and constructed quantitative Real-Time RT-PCR (RT-qPCR) mirEx 2 platform for barley's 159 pri-miRNAs (Zielezinski et al., 2015), we analyzed these pri-miRNAs as indicators of the barley response to drought and re-watering. In this study, two spring barley genotypes were used (Rolap and Sebas- tian). The plants were subjected to altered water regimes (mild and severe drought). The pri-miRNA expression variation was also assessed after soil rehydration. The obtained results were compared between the two genotypes. Our findings revealed that the pri-miRNA expression patterns are good markers of the stress level when analyzed globally. Additionally, individual pri-miRNAs are postulated to be used as drought stress or rehydration markers.

\section{MATERIALS AND METHODS}

Plant material and growth conditions. The spring barley seeds (the Rolap genotype - $\mathrm{DH}$ line derived from Roland and Apex cultivars) were received from the Institute of Plant Genetics of the Polish Academy of Sciences in Poznan, Poland (Devaux et al., 1992). The spring barley seeds (cultivar Sebastian) were received from the Faculty of Biology and Environmental Protection of the University of Silesia in Katowice (Poland). Barley plants were grown in a walk-in growth chamber (Conviron, Winnipeg, Manitoba, Canada), in 5L pots containing field soil mixed with sand $(7: 2)$. Soil was supplemented with a multinutrient fertilizer prior to sowing. Tillering plants were nourished with straight nitrogen fertilizer. Plants were grown at $22^{\circ} \mathrm{C}$ day $/ 15^{\circ} \mathrm{C}$ night temperatures and $16 \mathrm{~h}$ day $/ 8 \mathrm{~h}$ night photoperiods under $800 \mu \mathrm{mol}$ light conditions. Plants were watered to maintain 70\% SWC (Soil Water Content). Plants were subjected to drought/rehydration stress when their flag leaves appeared, stage 39-41 of the Zadoks cereal development decimal code (Zadoks et al., 1974). Drought stress was applied by withholding water, and the plants were collected when the SWC dropped to 30\% (mild drought) and 20\% (severe drought). 30\% SWC was reached $24 \mathrm{~h}$ after withholding water, and an additional $24 \mathrm{~h}$ was needed to reach $20 \%$ SWC. Rehydration to $70 \%$ SWC was applied when the SWC dropped to $10 \%$, and the plants were collected $6 \mathrm{~h}$ later. The shoots of four plants treated with one of the three conditions were pooled together and treated as one biological replicate. Plants were collected in three biological replicates. For each stressed sample, control plants were collected.

DNA and RNA isolation. Genomic DNA was isolated from $1 \mathrm{~g}$ of tissue from each genotype using a DNeasy Plant Maxi Kit (Qiagen, Hilden, Germany). DNA quantity and quality was estimated with a NanoDrop ND-1000 spectrophotometer. RNA was isolated from $100 \mathrm{mg}$ of tissue with $38 \%$ phenol saturated with $0.1 \mathrm{M}$ sodium acetate supplemented with $0.8 \mathrm{M}$ guanidine thiocyanate, $0.4 \mathrm{M}$ ammonium thiocyanate, $0.1 \mathrm{M}$ sodium acetate, 5\% glycerol, $0.5 \%$ sodium lauroylsarcosine, and $5 \mathrm{mM}$ EDTA. To remove polysaccharides, Ambion Plant RNA Isolation Aid (ThermoFisher Scientific, Waltham, MA, USA) was added during phenol extraction. RNA was precipitated with 1 volume of $0.8 \mathrm{M}$ sodium citrate in a $1.2 \mathrm{M}$ sodium chloride solution and 1 volume of isopropanol. RNA concentration and quality was measured with a NanoDrop ND-1000 spectrophotometer. RNA integrity was estimated on agarose gels. Contaminating DNA traces were removed with Ambion TURBO DNase (ThermoFisher Scientific, Waltham, MA, USA).

Quantitative Real-Time RT-PCR (RT-qPCR). $3 \mu \mathrm{g}$ of DNA-depleted RNA were reverse-transcribed with Invitrogen SuperScript III Reverse Transcriptase (ThermoFisher Scientific, Waltham, MA, USA) and $0.5 \mu \mathrm{g}$ Oligo(dT)18 Primer (ThermoFisher Scientific, 
Waltham, MA, USA). cDNA templates were 4-fold diluted. PCR of the PHT1.1 promoter fragment was performed to control the efficiency of the removal of DNA traces from the RNA samples (Kruszka et al., 2013). The cDNA purity control reactions were performed with DreamTaq DNA polymerase (ThermoFisher Scientific, Waltham, MA, USA) and two specific primers (500 nM each). RT-qPCR was performed with a 7900HT Fast Real-Time PCR System (Applied Biosystems) in 384well plates, in $10 \mu \mathrm{l}$ of reaction volume. Power SYBR Green PCR Master MIX (Applied Biosystems, Warrington, UK), two pri-miRNA-specific primers (final concentration of $200 \mathrm{nM}$ each), and $1 \mu \mathrm{l}$ of template were used for each reaction. Each RT-qPCR reaction was performed for three biological replicates. The barley ADP-ribosylation factor 1-like [GenBank: AJ508228.2] transcript fragment of $61 \mathrm{nt}$ was simultaneously amplified and detected as an internal reference (Rapacz et al., 2012). Expression levels were calculated with the relative quantification method $\left(2^{-\Delta \Delta \mathrm{Ct}}\right)$ as a fold-change value. The $\mathrm{R}^{2}$ values of the analyzed data $(\geq 0.997)$ were calculated with LinRegPCR software (Ramakers et al., 2003). The significance of the fold-change values was tested with a T-test. Primers designed and used for validation of the pri-miRNAs levels were complementary to the stem-loop structure containing the pri-miRNA fragment. The primers used were as described in Zielezinski and coworkers (2015). The pri-miRNA names were the same as in Zielezinski et al., 2015 (Table S1 at www.actabp.pl). Cycling conditions for PCR and RT-qPCR are provided in Supplementary Materials S1 (at www.actabp.pl).

\section{RESULTS AND DISCUSSION}

The study presented here concerned barley pri-miRNA expression variation under water-limiting conditions and recovery. Plants were stress treated during flag-leaf development, a developmental stage important for crop yield (Fig. 1). We have constructed a platform for the simultaneous and quantitative examination of 159 pri-miRNA expression levels. This platform was based on genomic sequences of three Hordeum vulgare cultivars (Morex, Barke, and Bowman) and tested on genomic DNA of two others (Rolap and Sebastian). Hence, we consider the pri-miRNA expression-analysis platform to be universal for domesticated barley. For 21 pri-miRNAs, we were unable to detect any expression in both, the control and stressed Rolap plants. We found that these pri-miRNAs were expressed in other abiotic stresses (data not shown) and were excluded from further analysis in experiments presented in this paper. Primers detecting 6 pri-miRNAs did not match the Sebastian cultivar. Altogether, the expression data contains 138 profiles of Rolap and 132 profiles of Sebastian miRNA primary transcripts under control, drought, and rehydration conditions. RT-qPCR is a well established technology dedicated for sensitive RNA quantification of a targeted set of genes (SEQC/MAQC-III Consortium, 2014). Other method for RNA quantification is RNA-seq. The detection sensitivity and quantification accuracy of RNA-seq depends on the read depth. Pri-miRNAs expression levels are low when compared to mRNAs. Hence, pri-miRNAs quantification with the RNA-seq method would require high coverage reads. Therefore, RT-qPCR is an optimal method for pri-miRNAs' expression analysis in terms of costs, sensitivity and quantification accuracy.

\section{Pri-miRNA levels altered by mild and severe drought}

We have grouped the pri-miRNA-relative expression patterns into three categories: (i) expression upregulated; (ii) expression unchanged; and (iii) expression downregulated. From the drought-treatment results, we concluded that pri-miRNA expression reflects the stress level applied to plants. Mild drought mostly downregulated pri-miRNAs (35 and 27 downregulated, 21 and 7 upregulated in the Rolap and Sebastian genotypes, respectively). The number of mild drought-reduced primiRNA expression was generally followed with severe drought in both genotypes (36 and 23 in the Rolap and Sebastian genotypes, respectively). Severe drought induced expression in 48 and 21 of pri-miRNAs in the Rolap and Sebastian genotypes, respectively. Thus,
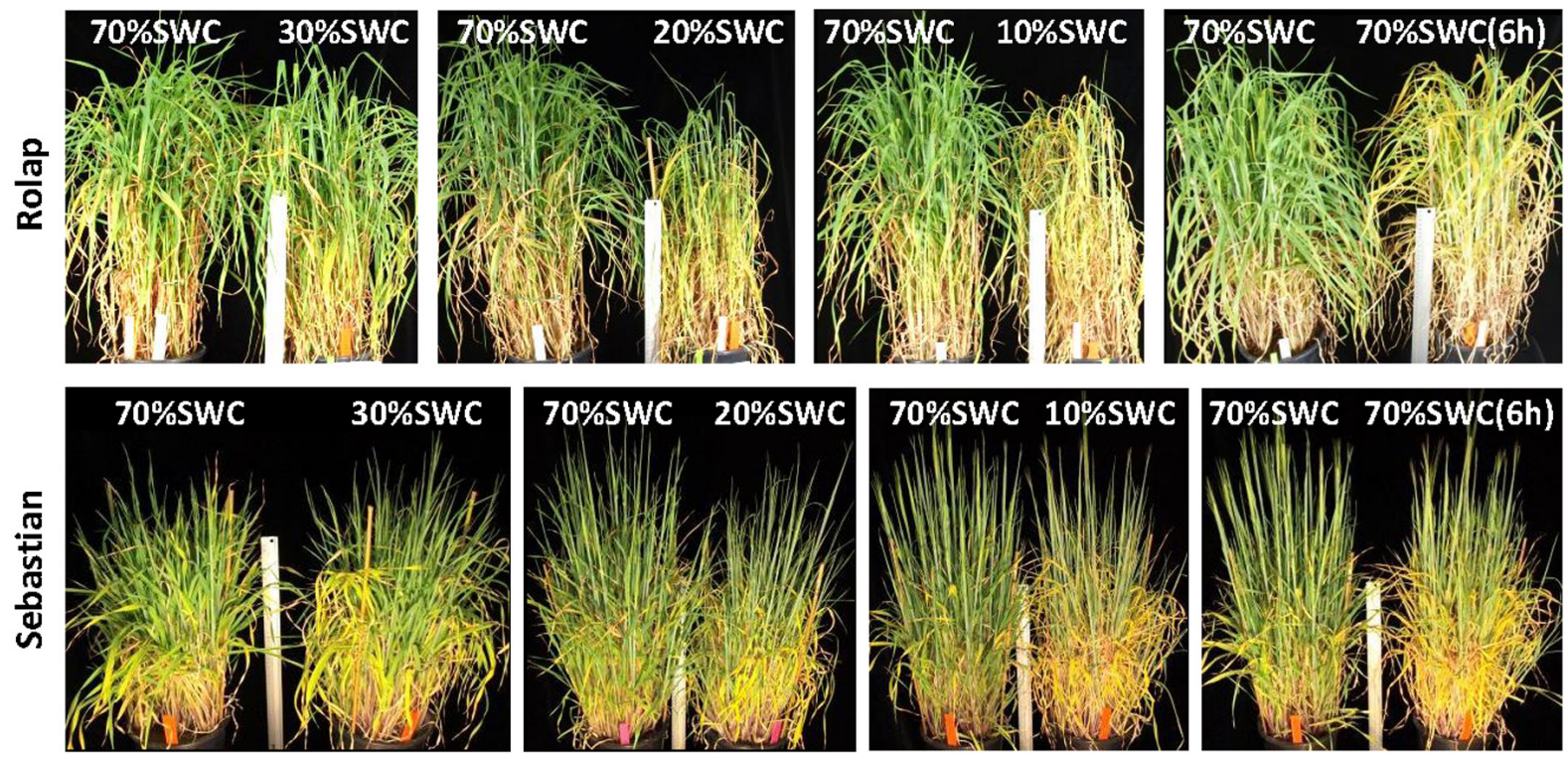

Figure 1. Control, mild drought, severe drought, and rehydration treated plants of two barley genotypes (Rolap and Sebastian). $70 \%$ SWC, control; $30 \%$ SWC, mild drought; $20 \%$ SWC, severe drought; $10 \%$, severe drought (not tested in the study); $70 \%$ SWC (6 h), rehydration. 
Table 1. General tendencies in pri-miRNA expression in two Hordeum vulgare genotypes (Rolap and Sebastian) altered by mild drought, severe drought, and rehydration.

$\uparrow$ - upregulated, $\downarrow$ - downregulated, = - unchanged.

\begin{tabular}{llllllllll}
\hline & \multicolumn{2}{l}{ mild drought } & \multicolumn{3}{l}{ severe drought } & \multicolumn{2}{c}{ rehydration } \\
\hline & $\uparrow$ & $=$ & $\downarrow$ & $\uparrow$ & $=$ & $\downarrow$ & $\uparrow$ & $=$ & $\downarrow$ \\
Rolap & 20 & 25 & 24 & 38 & 18 & 21 & 38 & 25 & 19 \\
\hdashline Sebastian & 6 & 40 & 16 & 11 & 53 & 8 & 6 & 51 & 18 \\
both & 1 & 57 & 11 & 10 & 35 & 15 & 10 & 35 & 11 \\
\hline
\end{tabular}

while mild drought's dominant feature was a decrease in the pri-miRNA expression, severe drought stands out by the induction of pri-miRNAs. From this data, we cannot conclude whether this was due to the strength of stress or duration of the drought treatment (24 $\mathrm{h}$ for $30 \%$ SWC and $48 \mathrm{~h}$ for $20 \%$ SWC). However, our studies of the mature miRNAs showed that even prolonged mild drought did not significantly influence their levels (data not shown). Under rehydration conditions, the level of 78 Rolap pri-miRNAs was affected (48 were upregulated, and the expression of 30 pri-miRNAs was decreased). The water re-supply in the Sebastian genotype upregulated 16 pri-miRNAs, downregulated 29 of them (45 pri-miRNAs altered), and did not influence the level of 86 pri-miRNAs. The re-watering study suggests that six hours of optimal water supply was not sufficient to reverse the severe-droughtinduced changes in the pri-miRNA expression. Previously, comprehensive studies on pri-miRNA expression under drought treatment were conducted only in Arabidopsis (Barciszewska-Pacak et al., 2015). Arabidopsis and barley pri-miRNA response to drought was similar. Mild drought mostly downregulated the ath-pri-miRNAs, while the main feature of severe drought was athpri-miRNAs upregulation. Summary of these analyses is presented in Table 1.

\section{Pri-miRNA level dynamics during mild to severe drought transition}

As mentioned earlier, pri miRNA expression was mainly decreased under mild drought conditions. In the Rolap genotype, we observed that 18 of the downregulated pri-miRNAs in the mild drought treated plants were also downregulated in case of severe drought (Fig. 2, Table S2 at www.actabp.pl). Surprisingly, there was a set of 17 mild drought downregulated pri-miRNAs that responded to severe drought by induction of their expression. The expression of nine of them returned to the control level under severe drought, and the remaining eight were even upregulated. Similarly, in Sebastian we identified 12 mild and severe drought downregulated pri-miRNAs and 15 in which expression was decreased under mild drought and induced during the severe drought stress.

A group of 21 pri-miRNAs was induced by mild drought in the Rolap genotype. Their expression mostly stayed upregulated under severe drought, except for one that was strongly decreased under severe drought and further under rehydration. The Sebastian cultivar showed mild drought-induced levels for only seven pri-miRNAs. Three of them were constantly induced under severe drought.

Mature miRNA expression dynamics is not always reflected by their cognate pri-miRNA expression lev-
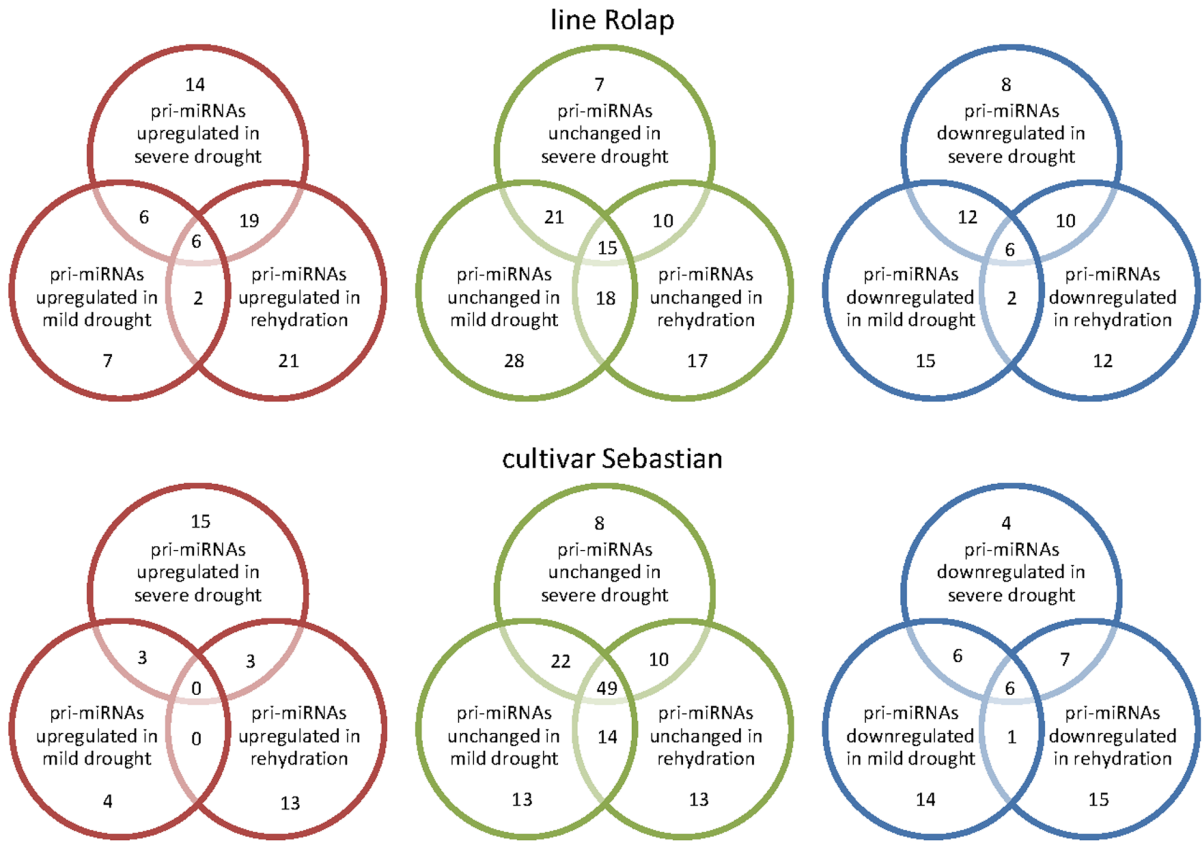

Figure 2. Diagrams showing relations between the pri-miRNA category of different treatments.

Each diagram shows one category of pri-miRNAs: upregulated, unchanged, and downregulated. The barley Rolap, and Sebastian genotypes pri-miRNA expression data are shown on separate diagram sets. 
Table 2. Pri-miRNA169 expression under mild drought, severe drought, and rehydration in two Hordeum vulgare genotypes (Rolap and Sebastian).

RTqPCR results are shown as fold-change values. The levels of pri-miRNAs under the control conditions were assumed to be ' 1 ', and the levels of pri-miRNAs under stress conditions were quantified in relation to this standard. The up- and down-regulated pri-miRNAs were suggested by a two-tailed Student's $t$-test $\left({ }^{* * *} p \leq 0.001,{ }^{* *} p \leq 0.01,{ }^{*} p \leq 0.05\right)$. Up, down-regulated pri-miRNAs are marked as red and blue, respectively (nd, not detected).

\begin{tabular}{|c|c|c|c|c|c|c|}
\hline & Rolap & & & Sebastian & & \\
\hline pri-miRNA & mild drought & severe drought & rehydration & mild drought & severe drought & rehydration \\
\hline $169 f$ & $2.17^{* *}$ & $5.88^{*}$ & 1.29 & 1.59 & $3.38^{*}$ & 9.41 \\
\hline $169 \mathrm{~h}$ & 1.44 & 2.53 & $2.05^{*}$ & 1.21 & 1.80 & $2.68^{* * *}$ \\
\hline $169 d$ & 1.13 & 0.84 & $2.56^{*}$ & 0.63 & 0.84 & 1.44 \\
\hline $169 a$ & 1.18 & 1.30 & $1.31^{*}$ & 3.62 & 6.54 & $0.03^{* * *}$ \\
\hline $169 m$ & $1.32 *$ & $0.35^{* *}$ & $0.10^{* * *}$ & 0.89 & 1.20 & $0.36^{* *}$ \\
\hline $169 e$ & 2.43 & $0.12^{* * *}$ & $0.14^{* * *}$ & 0.71 & $0.38^{*}$ & $0.35^{* *}$ \\
\hline $169 c$ & $0.75^{* *}$ & $0.75^{* *}$ & 3.65 & nd & nd & nd \\
\hline
\end{tabular}

els. This was thoroughly studied in Arabidopsis under many abiotic stresses (Barciszewska-Pacak et al., 2015). The data presented by Barciszewska-Pacak and coworkers (2015) showed that the level of particular miRNA could not be predicted based on the level of its particular pri-miRNA. Hence, the most probable cause of miRNA expression fluctuations are changes in the primiRNA processing. Pri-miRNAs undergo posttranscriptional processes like splicing, alternative splicing and alternative polyadenylation site selection. Posttranscriptional pri-miRNAs' processing is correlated with mature miRNAs' expression levels (Bielewicz et al., 2013; Jia \& Rock, 2013). Yan and coworkers (2012) showed that heat stress induced alternative splicing event led to Arabidopsis pri-miRNA400 accumulation which resulted in the mature miRNA400 decrease. It was shown that during salt stress in Arabidopsis, in some cases, the decreased level of pri-miRNAs correlated with increased accumulation of mature miRNAs and not their complementary miRNAs* (Dolata et al., 2016). This was due to AGO1 binding and stabilization of these miRNAs. Changes in pri-miRNA levels could be the result of the MIR expression regulation at the level of transcription. Abiotic stress response elements were computationally predicted in promoter regions of many Arabidopsis miRNA genes (Megraw et al., 2006; Zhao et al., 2013). Transcriptional regulation of MIR can explain the observed expression fluctuations in case of some Arabidopsis or barley pri-miRNAs. Nevertheless, drought responsive elements in the barley MIR are not known. An interesting observation was made in $A$. thaliana and Solanum tuberosum, where a consequence of CBP8O expression-silencing was a decrease in mature miRNA159 (Pieczynski et al., 2013). CBP80 and CBP20 are known to be involved in pri-miRNA maturation and affect the level of several mature miRNAs (Szarzynska et al., 2009; Laubinger et al., 2008; Raczynska et al., 2010; Raczynska et al., 2014). Downregulation of the miR159 level caused MYB33 target gene expression upregulation and induced Arabidopsis and potato drought tolerance and hypersensitivity to ABA. As pri-miRNA biogenesis is a multistep process, there are many ways to posttranscriptionally regulate $M I R$ transcripts. We concluded that drought stress-induced changes in the pri-miRNA expression pattern may also affect the level of mature miRNAs.

\section{Severe drought-induced changes in pri-miRNA expression can be reversed during rehydration}

As stated earlier, severe drought mainly induced primiRNA expression in the Rolap variety (Table 1). In contrast, rehydration allowed the reversion of expression of 23 severe drought-induced pri-miRNAs (out of 48) to control or even lower levels, already within six hours of rehydration (Table S2 at www.actabp.pl). The remaining 25 drought-induced pri-miRNAs remained upregulated after $6 \mathrm{~h}$ of water re-supply (Fig. 2). Similarly, drought downregulated expression returned to control or increased levels for 20 out of the 36 pri-miRNAs.

In barley plants of the Rolap genotype, rehydration surprisingly induced the expression of 19 pri-miRNAs. Their expression was not affected by severe drought (Table S2 at www.actabp.pl). In addition, expression of 10 pri-miRNAs not affected by severe drought was reduced after water re-supply.

Interestingly, the pri-miRNA expression study for the Sebastian cultivar gave slightly different results. Of the 21 pri-miRNAs upregulated under severe drought, 17 pri-miRNA expression levels returned to their initial level of expression with rehydration. Thus, severe droughtinduced pri-miRNA levels were mainly reversed by rewatering in the Sebastian cultivar. In the Rolap line, this was observed only for 23 out of 48 pri-miRNAs. The Rolap and Sebastian genotypes were never compared in terms of their water-depletion stress resistance. Moreover, neither of these genotypes were studied toward drought resistance. The differences in pri-miRNA expression may suggest drought-resistance dissimilarity between these two genotypes. Our results indicated that the Rolap line susceptibility to water supply limitations is higher than Sebastian's. Our observation was strengthened by the fact that one of the Rolap parents is the highly drought intolerant Roland cultivar (http://agris. fao.org/agris-search/search.do?recordID=PL9201081).

Of the 16 pri-miRNAs upregulated upon rehydration in Sebastian, 13 pri-miRNAs were recognized as specifically rehydration induced. Thus, rehydration additionally stimulated new changes in the pri-miRNA expression. Severe drought decreased the expression of 23 pri-miRNAs in Sebastian. The level of these pri-miRNAs returned to the initial level after re-watering in case of 10 pri-miRNAs. 
Table 3. A list of pri-miRNAs identified as markers of drought-, mild drought-, or rehydrationtreated barley plants.

\begin{tabular}{|c|c|c|c|c|c|}
\hline \multirow{17}{*}{ 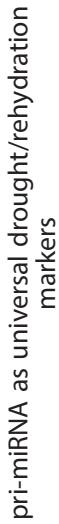 } & \multicolumn{2}{|c|}{ drought } & \multirow{2}{*}{$\frac{\text { mild drought }}{\text { downregulated }}$} & \multicolumn{2}{|c|}{ rehydration } \\
\hline & upregulated & downregulated & & upregulated & downregulated \\
\hline & $160 f$ & $160 a$ & $1130 b$ & $159 a$ & $164 a$ \\
\hline & $167 \mathrm{~b}$ & $169 e$ & $399 c$ & $159 c$ & $2118 c$ \\
\hline & $169 f$ & $166 j$ & 5049h & 169h & $5049 b$ \\
\hline & $171 \mathrm{~b}$ & $171 \mathrm{c}$ & & 1120 & 6183 \\
\hline & $2275 a$ & $172 c$ & & 6212 & \\
\hline & $399 c$ & $319 b$ & & $9674 b$ & \\
\hline & $399 e$ & $396 c$ & & & \\
\hline & $5048 a$ & $398 a$ & & & \\
\hline & $5049 e$ & 399a & & & \\
\hline & 6199 & 5052 & & & \\
\hline & & 5168 & & & \\
\hline & & 6176 & & & \\
\hline & & 6207 & & & \\
\hline & & 6208 & & & \\
\hline & & 6211 & & & \\
\hline
\end{tabular}

\section{Pri-miRNA169 expression under drought and rehydration}

The MiRNA169 family was shown to be involved in drought resistance in Arabidopsis and Solanum lycopersicum. Water deficit or abscisic acid (ABA) treatment decreased the ath-miRNAs169a/c (Li et al., 2008). These miRNAs target the mRNA of NFYA5, a subunit of transcription factor NF-Y. NFYA5 acts in stomata cells, decreasing transpiration in an ABA-dependent way. The overexpression of MIR169a had caused a higher drought intolerance in Arabidopsis. Moreover, the deletion of MIR169a generated a drought-resistance phenotype (Zhao et al., 2016). In contrast, in S. lycopersicum, the drought-induced accumulation of miRNA169 and, consequently, the overexpression of miRNA169c, triggered a drought-tolerant phenotype (Zhang et al., 2011). Our study showed that members of the pri-miRNA169 family were differentially regulated under drought/rehydration stress (Table 2). The MiRNA169 family members are good candidates for inducing drought tolerance in barley.

\section{Pri-miRNAs as water limitation/re-supply markers}

As drought can be correlated with several pri-miRNA expression profiles, we have proposed a set of mild drought, drought, and rehydration markers. The selected pri-miRNAs responded similarly in both of the tested genotypes (Table 3).

Severe drought upregulated the expression of 10 orthologous pri-miRNAs in Rolap and Sebastian, while 15 orthologous pri-miRNAs were downregulated in both genotypes (Table 3). These 25 pri-miRNAs are proposed to be the drought-stress markers. Mild drought could be identified by the fact that pri-miRNA1130b, pri-miRNA399c, and pri-miRNA5049h levels decreased. These precursors were only downregulated in the Rolap and Sebastian under mild drought. We propose to use 10 pri-miRNAs as markers of plant recovery from drought. Rehydration in barley induced the expression of six orthologous pri-miRNAs in Rolap and Sebastian. Profiles of these pri-miRNAs were downregulated or not affected by mild and severe drought. Other rehydration markers could be four pri-miRNAs (pri-miRNA164a, primiRNA2118c, pri-miRNA5049b, and pri-miRNA6183), whose levels were reduced regardless of the variety tested. This is the first study where pri-miRNAs were analyzed as stress markers.

Drought induces complex changes in plants, which leads to growth and development inhibition. Our study showed that pri-miRNAs respond strongly to drought. The usage of primiRNAs' RT-qPCR platform under three different water limitation/rehydration regimes revealed differential MIR gene reprograming among the three treatments. We recommend the primary microRNA RT-qPCR-based platform to be a universal tool for testing the strength of drought response in barley. Hence, the platform can be used to determine the drought stress levels applied to barley plants. Also, it would be beneficial to use the pri-miRNAs RT-qPCR platform in studies on barley transition between drought response and drought acclimation. MicroRNAs in barley's homeostasis under prolonged drought were not yet studied. Pri-miRNAs expression studies can be used to reveal candidates for future genetic analysis when looking for drought tolerance/resistance markers. As miRNAs mostly regulate the transcription-factor expression, they are excellent candidates for plant biotechnological studies. MIR's inactivation became possible with CRISPR/Cas9 technology (Zhao et al., 2016). It would be interesting to recognize which miRNAs activate plant drought-rescue pathways. Genes regulated by miRNAs are subsequent objectives for such studies. The pri-miRNAs RT-qPCR platform can be also used to test barley response under other abiotic and biotic stresses.

\section{Acknowledgements}

This work was supported by the European Regional Development Fund through the Innovative Economy for Poland 2007-2013, project WNDPOIG.01.03.01-00-101/08/01 POLAPGEN-BD "Biotechnological tools for breeding cereals with increased resistance to drought" and by the KNOW RNA Research Centre in Poznan 01/KNOW2/2014.

\section{REFERENCES}

Alaba S, Piszczalka P, Pietrykowska H, Pacak AM, Sierocka I, Nuc PW, Singh K, Plewka P, Sulkowska A, Jarmolowski A, Karlowski WM, Szweykowska-Kulinska Z (2015) The liverwort Pellia endiviifolia shares microtranscriptomic traits that are common to green algae and land plants. New Phytol 206: 352-367. doi: 10.1111/nph.13220

Altschul SF, Gish W, Miller W, Myers EW, Lipman DJ (1990) Basic local alignment search tool. J Mol Biol 215: 403-410. doi: 10.1016/ S0022-2836(05)80360-2

Aukerman MJ, Sakai H (2003) Regulation of flowering time and floral organ identity by a MicroRNA and its APETALA2-like target genes. Plant Cell 15: 2730-2741. doi: 10.1105/tpc.016238

Barciszewska-Pacak M, Milanowska K, Knop K, Bielewicz D, Nuc P, Plewka P, Pacak AM, Vazquez F, Karlowski W, Jarmolowski A, Szweykowska-Kulinska Z (2015) Arabidopsis microRNA expression regulation in a wide range of abiotic stress responses. Front Plant Sci 6: 410. doi: $10.3389 /$ fpls.2015.00410

Bartel DP (2004) MicroRNAs: Genomics, Biogenesis, Mechanism, and Function. Cell 116: 281-297. doi: 10.1016/S0092-8674(04)00045-5

Bielewicz D, Dolata J, Zielezinski A, Alaba S, Szarzynska B, Szczesniak MW, Jarmolowski J, Szweykowska-Kulinska Z, Karlowski W (2012) mirEX: a platform for comparative exploration of plant pri-miRNA expression data. Nucleic Acid Res 40: 191-197. doi: 10.1093/nar/ gkr878

Bielewicz D, Kalak M, Kalyna M, Windels D, Barta A, Vazquez F, Szweykowska-Kulinska Z, Jarmolowski A (2013) Introns of plant 
pri-miRNAs enhance miRNA biogenesis. EMBO Rep 14: 622-628. doi: 10.1038/embor.2013.62

Boualem A, Laporte P, Jovanovic M, Laffont C, Plet J, Combier JP, Niebel A, Crespi M, Frugier F (2008) MicroRNA166 controls root and nodule development in Medicago truncatula. The Plant Journal 54: 876-887. doi: 10.1111/j.1365-313X.2008.03448.x

Brodersen P, Sakvarelidze-Achard L, Bruun-Rasmussen M, Dunoyer P, Yamamoto YY, Sieburth L, Voinnet O (2008) Widespread translational inhibition by plant miRNAs and siRNAs. Science 320: 11851190. doi: $10.1126 /$ science. 1159151

Brown JWS, Marshall DF, Echeverria M (2008) Intronic noncoding RNAs and splicing. Trends Plant Sci 13: 335-342. doi: 10.1016/j. tplants.2008.04.010.

Carthew RW, Sontheimer EJ (2009) Origins and mechanisms of miRNAs and siRNAs. Cell 136: 642-655. doi: 10.1016/j.cell.2009.01.035

Chen X (2004) A microRNA as a translational repressor of APETALA2 in Arabidopsis flower development. Science 303: 2022-2025. doi: $10.1126 /$ science. 1088060

Chen X, Zhang Z, Liu D, Zhang K, Li A, Mao L (2010) SQUAMOSA promoter-binding protein-like transcription factors: star players for plant growth and development. I Integr Plant Biol 52: 946-951. doi: 10.1111/j.1744-7909.2010.00987.x

Deng W, Nickle DC, Learn GH, Maust B, and Mullins JI (2007) ViroBLAST: A stand-alone BLAST web server for flexible queries of multiple databases and user's datasets. Bioinformatics 23: 2334-2336. doi: 10.1093/bioinformatics/btm331

Devaux P, Adamski T. Surma M (1992) Inheritance of seed set in crosses of spring barley and Hordeum bulbosum L. Crop Sci 32: 269271. doi: $10.2135 /$ cropsci1992.0011183X003200010054x

Dolata J, Bajczyk M, Bielewicz D, Niedojadlo K, Niedojadlo J, Pietrykowska H, Walczak W, Szweykowska-Kulinska Z, Jarmolowski A.(2016) Salt stress reveals a new role for ARGONAUTE 1 in miRNA biogenesis at the transcriptional and post-transcriptional levels. Plant Physiol. Jul 6. pii: pp.00830.2016. [Epub ahead of print]

Eamens AL, Smith NA, Curtin SJ, Wang MB, Waterhouse PM (2009) The Arabidopsis thaliana double-stranded RNA binding protein DRB1 directs guide strand selection from microRNA duplexes. RNA 15: 2219-2235. doi: 10.1261/rna.1646909

Hackenberg M, Gustafson P, Langridge P, Shi BJ (2015) Differential expression of microRNAs and other small RNAs in barley between water and drought conditions. Plant Biotechnol J 13, pp 2-13. doi: $10.1111 /$ pbi. 12220

Hofacker IL, Fontana W, Stadler PF, Bonhoeffer LS, Tacker M, Schuster P (1994) Fast folding and comparison of RNA secondary structures (The Vienna RNA Package). Monatsh Chem 125: 167-188. doi: $10.1007 / \mathrm{BF} 00818163$

International Barley Genome Sequencing Consortium, Mayer KF, Waugh R, Brown JW, Schulman A, Langridge P, Platzer M, Fincher GB, Muehlbauer GJ, Sato K, Close TJ, Wise RP, Stein N (2012) A physical, genetic and functional sequence assembly of the barley genome. Nature 491: 711-716. doi: 10.1038/nature11543

Jia F, and Rock CD (2013) MIR846 and MIR842 comprise a cistronic MIRNA pair that is regulated by abscisic acid by alternative splicing in roots of Arabidopsis. Plant Mol Biol 81: 447-460. doi: 10.1007/ s11103-013-0015-6

Jian X, Zhang L, Li G, Zhang L, Wang X, Cao X, Fang X, Chen $F$ (2010) Identification of novel stress regulated microRNAs from Oryza sativa L. Genomics 95: 47-55. doi: 10.1016/j.ygeno.2009.08.017

Kantar M, Unver T, Budak H (2010) Regulation of barley miRNAs upon dehydration stress correlated with target gene expression. Funct Integr Genomics 10: 493-507. doi: 10.1007/s10142-010-0181-4

Katoh K, Toh H (2008) Recent developments in the MAFFT multiple sequence alignment program. Brief Bioinform 9: 286-298. doi: 10.1093/bib/bbn013

Khraiwesh B, Zhua JK, Zhuc J (2012) Role of miRNAs and siRNAs in biotic and abiotic stress responses of plants. Biochim Biophys Acta 1819: 137-148. doi: 10.1016/j.bbagrm.2011.05.001

Kozomara A, Griffiths-Jones S (2014) miRBase:annotating high confidence microRNAs using deep sequencing data. Nucleic Acids Res 42: D68-D73. doi: 10.1093/nar/gkt1181

Kruszka K, Pieczynski M, Windels D, Bielewicz D, Jarmołowski A, Szweykowska-Kulinska Z, Vazques F (2012) Role of microRNAs and Rother sRNAs of plants in their changing environment. J Plant Physiol 169: 1664-1672. doi: 10.1016/j.jplph.2012.03.009

Kruszka K, Pacak A, Swida-Barteczka A, Stefaniak AK, Kaja E, Sierocka I, Karlowski W, Jarmolowski A, Szweykowska-Kulinska Z (2013) Developmentally regulated expression and complex processing of barley pri-microRNAs. BMC Genomics 14: 34. doi: 10.1186/1471-2164-14-34

Kruszka K, Pacak A, Swida-Barteczka A, Nuc P, Alaba S, Wroblewska Z, Karlowski W, Jarmolowski A, Szweykowska-Kulinska Z (2014) Transcriptionally and post-transcriptionally regulated microRNAs in heat stress response in barley. J Exp Bot 65: 6123-6235. doi: 10.1093/jxb/eru353

Kurihara Y, Takashi Y, Watanabe Y (2006) The interaction between DCL1 and HYL1 is important for efficient and precise processing of pri-miRNA in plant microRNA biogenesis. RNA 12: 206-212. doi: $10.1261 /$ rna.2146906

Lacombe S, Nagasaki H, Santi C, Duval D, Piegu B, Bangratz M, Breitler JC, Guiderdoni E, Brugidou C, Hirsch J, Cao X, Brice C, Panaud O, Karlowski WM, Sato Y, Echeverria M (2008) Identification of precursor transcripts for 6 novel miRNAs expands the diversity on the genomic organisation and expression of miRNA genes in rice. BMC Plant Biol 8: 123. doi: 10.1186/1471-2229-8-123

Laubinger S, Sachsenberg T, Zeller G, Busch W, Lohmann JU, Ratsch G, Weigel D (2008) Dual roles of the nuclear cap-binding complex and SERRATE in pre-mRNA splicing and micro RNA processing in Arabidopsis thaliana. Proc Natl Acad Sci USA 105: 8795-8800. doi: 10.1073/pnas.0802493105

Lee Y, Kim M, Han J, Yeom KH, Lee S, Baek SH, Kim VN (2004) MicroRNA genes are transcribed by RNA polymerase II. EMBO J 23: 4051-4060. doi: 10.1038/sj.emboj.7600385

Lee Y, Jeon K, Lee JT, Kim S, Kim VN (2002) MicroRNA maturation: stepwise processing and subcellular localization. EMBO J 21: 4663-4670. doi: $10.1093 / \mathrm{emboj} / \mathrm{cdf} 476$

Li WX, Ono Y, Zhu J, He XJ, Wu JM, Iida K, Lu XY, Cui X, Jin $\mathrm{H}$, Zhu JK (2008) The Arabidopsis NFYA5 transcription factor is regulated transcriptionally and posttranscriptionally to promote drought resistance. The Plant Cell 20: 2238-2251. doi: 10.1105/ tpc.108.059444

Li YP, Ye, W, Wang M, Yan XD (2009) Climate change and drought: a risk assessment of crop-yield impacts. Clim Res 39: 31-46. doi: $10.3354 / \mathrm{cr} 00797$

Liu HH, Tian X, Li YJ, Wu CA, Zheng CC (2008) Microarray-based analysis of stress-regulated microRNAs in Arabidopsis thaliana. RNA 14: 836-843. doi: 10.1261/ rna.895308

Llave C, Xie Z, Kasschau KD, Carrington JC (2002) Cleavage of Scarecrow-like mRNA targets directed by a class of Arabidopsis miRNA. Science 297: 2053-2056. doi: 10.1126/science.1076311

Lv S, Nie X, Wang L, Du X, Biradar SS, Jia X, Weining S (2012) Identification and characterization of MicroRNAs from barley (Hordeum vulgare L.) by high-throughput sequencing. Int J Mol Sci 13: 2973 2984. doi: $10.3390 /$ ijms 13032973

Mallory AC, Reinhart BJ, Jones-Rhoades MW, Tang G, Zamore PD, Barton MK, Bartel DP (2004) MicroRNA control of PHABULOSA' in leaf development: importance of pairing to the microRNA 5' region. EMBO J 23: 3356-3364. doi: 10.1038/sj.emboj.7600340

McConnell JR, Emery J, Eshed Y, Bao N, Bowman J, Barton MK (2001) Role of PHABULOSA and PHAVOLUTA in determining radial patterning in shoots. Nature 411: 709-713. doi: 10.1038/35079635

Megraw M, Baev V, Rusinov V, Jensen S T, Kalantidis K, and Hatzigeorgiou AG (2006) MicroRNA promoter element discovery in Arabidopsis. RNA 12: 1612-1619. doi: 10.1261/rna.130506

Palatnik JF, Allen E, Wu X, Schommer C, Schwab R, Carrington JC, Weigel D (2003) Control of leaf morphogenesis by miRNAs. Nature 425: 257-263. doi: $10.1038 /$ nature 01958

Park MY, Wu G, Gonzalez-Sulser A, Vaucheret H, Poethig RS (2005) Nuclear processing and export of microRNAs in Arabidopsis. Proc Natl Acad Sci USA 102: 3691-3696. doi: 10.1073/pnas.0405570102

Pieczynski M, Marczewski W, Hennig J, Dolata J, Bielewicz D, Piontek P, Wyrzykowska A, Krusiewicz D, Strzelczyk-Zyta D, KonopkaPostupolska D, Krzeslowska M, Jarmolowski A, Szweykowska-Kulinska Z (2013) Down-regulation of CBP80 gene expression as a strategy to engineer a drought-tolerant potato. Plant Biotecbnol J 11: 459-469. doi: $10.1111 /$ pbi.12032

Raczynska KD, Simpson CG, Ciesiolka A, Szewc L, Lewandowska D, McNicol J, Szweykowska-Kulinska Z, Brown JWS, Jarmolowski A' (2010) Involvement of the nuclear cap-binding protein complex in alternative splicing in Arabidopsis thaliana. Nucleic Acids Res 38: 265278. doi: $10.1093 / \mathrm{nar} / \mathrm{gkp} 869$

Raczynska KD, Stepien A, Kierzkowski D, Kalak M, Bajczyk M, McNicol J, Simpson CG, Szweykowska-Kulinska Z, Brown JW, Jarmolowski A (2014) The SERRATE protein is involved in alternative splicing in Arabidopsis thaliana. Nucleic Acids Res. 42: 1224-1244. doi: $10.1093 / \mathrm{nar} / \mathrm{gkt} 894$

Rajagopalan R, Vaucheret H, Trejo J, Bartel DP (2006) A diverse and evolutionarily fluid set of microRNAs in Arabidopsis thaliana. Genes Dev 20: 3407-3425. doi: 10.1101/gad.1476406

Ramakers C, Ruijter JM, Deprez RH, Moorman AFM (2003) Assumption-free analysis of quantitative real-time polymerase chain reaction (PCR) data. Neurosci Lett 339: 62-66. doi: 10.1016/S03043940(02)01423-4

Rapacz M, Stepien A, Skorupa K (2012) Internal standards for quantitative RT-PCR studies of gene expression under drought treatment in barley (Hordeum vulgare L.): the effects of developmental stage and leaf age. Acta Physiol Plant 34: 1723-1733. doi: 10.1007/s11738-0120967-1

Rogers K, Chen X (2013) Biogenesis, turnover, and mode of action of plant microRNAs. Plant Cell 25: 2383-2399. doi: 10.1105/ tpc.113.113159 
Ru P, Xu L, Ma H, Huang H (2006) Plant fertility defects induced by the enhanced expression of microRNA167. Cell Res 16: 457-465. doi: $10.1038 /$ sj.cr.7310057

Schreiber AW, Shi BJ, Huang CY, Langridge P, Baumann U (2011) Discovery of barley miRNAs through deep sequencing of short reads. BMC Genomics 25: 129. doi: 10.1186/1471-2164-12-129

SEQC/MAQC-III Consortium. Su Z, Labaj PP, Li S, Thierry-Mieg J, Thierry-Mieg D, Shi W, Wang C, Schroth GP, Setterquist RA, Thompson JF, Jones WD, Xiao W, Xu W, Jensen RV, Kelly R, Xu J, Conesa A, Furlanello C, Gao H, Hong H, Jafari N, Letovsky S, Liao Y, Lu F, Oakeley EJ, Peng Z, Praul CA, Santoyo-Lopez J, Scherer A, Shi T, Smyth GK, Staedtler F, Sykacek P, Tan XX, Thompson EA, Vandesompele J, Wang MD, Wang J, Wolfinger RD, Zavadil J, Auerbach SS, Bao W, Binder H, Blomquist T, Brilliant $\mathrm{MH}$, Bushel PR, Cai W, Catalano JG, Chang CW, Chen T, Chen G, Chen R, Chierici M, Chu TM, Clevert DA, Deng Y, Derti A, Devanarayan V, Dong Z, Dopazo J, Du T, Fang H, Fang Y, Fasold M, Fernandez A, Fischer M, Furió-Tari P, Fuscoe JC, Caimet F, Gaj S, Gandara J, Gao H, Ge W, Gondo Y, Gong B, Gong M, Gong Z, Green B, Guo C, Guo L, Guo LW, Hadfield J, Hellemans J, Hochreiter S, Jia M, Jian M, Johnson CD, Kay S, Kleinjans J, Lababidi S, Levy S, Li QZ, Li L, Li L, Li P, Li Y, Li H, Li J, Li S, Lin SM, López FJ, Lu X, Luo H, Ma X, Meehan J, Megherbi DB, Mei N, Mu B, Ning B, Pandey A, Pérez-Florido J, Perkins RG, Peters R, Phan JH, Pirooznia M, Qian F, Qing T, Rainbow L, Rocca-Serra P, Sambourg L, Sansone SA, Schwartz S, Shah R, Shen J, Smith TM, Stegle O, Stralis-Pavese N, Stupka E, Suzuki Y, Szkotnicki LT, Tinning M, Tu (2014) A comprehensive assessment of RNA-seq accuracy, reproducibility and information content by the Sequencing Quality Control Consortium. Nat Biotechnol 32: 903-914. doi: $10.1038 / \mathrm{nbt} .2957$

Song L, Han MH, Lesicka J, Fedoroff N (2007) Arabidopsis primary microRNA processing proteins HYL1 and DCL1 define a nuclear body distinct from the Cajal body. Proc Natl Acad Sci USA 104: 5437-5442. doi: 10.1073/pnas.0701061104

Sunkar R, Kapoor A, Zhu JK (2006) Posttranscriptional induction of two $\mathrm{Cu} / \mathrm{Zn}$ superoxide dismutase genes in Arabidopsis is mediated by downregulation of miR398 and important for oxidative stress tolerance. Plant Cell 18: 2051-2065. doi: 10.1105/tpc.106.041673

Sunkar R, Zhu JK (2004) Novel and stress-regulated microRNAs and other small RNAs from Arabidopsis. Plant Cell 16: 2001-2019. doi: $10.1105 /$ tpc. 104.022830

Szarzynska B, Sobkowiak L, Jarmolowski A, Szweykowska-Kulinska Z (2011) Gene structures and processing of plant pri-miRNAs. Res Adv in Nucleic Acids Res 1: 1-12.

Szarzyńska B, Sobkowiak , Pant BD, Balazadeh S, Scheible WR, Mueller-Roeber B, Jarmołowski A, Szweykowska-Kulińska Z (2009) Gene structure and processing of Arabidopsis thaliana HYL1-dependent pri-miRNAs. Nucleic Acids Res 37: 3083-3093. doi: 10.1093/nar/ gkp189

Szwed M, Karg G, Pińskwar I, Radziejewski M, GraczykD, Kędziora A, Kundzeiwcz ZW (2010) Climate change and its effect on agriculture, water resources and human health sectors in Poland. Nat Hazards Earth Syst Sci 10: 1725-1737. doi: 10.5194/nhess-10-1725-2010

Szweykowska-Kulińska Z, Jarmołowski A, Vazquez F (2013) The crosstalk between plant microRNA biogenesis factors and the spliceosome. Plant Signal Behav 8: e26955. doi: 10.4161/psb.26955

Talmor-Neiman M, Stav R, Frank W, Voss B, Arazi T (2006) Novel micro-RNAs and intermediates of micro-RNA biogenesis from moss. Plant J 47: 25-37. doi: 10.1111/j.1365-313X.2006.02768.x

Untergasser A, Nijveen H, Rao X, Bisseling T, Geurts R, Leunissen JA (2007) Primer3Plus, an enhanced web interface to Primer3. Nucleic Acids Res 35: W71-W74. doi: 10.1093/nar/gkm306
Vaucheret H, Vazquez F, Crété P, Bartel DP (2004) The action of ARGONAUTE1 in the miRNA pathway and its regulation by the miRNA pathway are crucial for plant development. Genes Dev 18: 1187-1197. doi: 10.1101/gad.1201404

Wu MF, Tian Q, Reed JW (2006) Arabidopsis microRNA167 controls patterns of ARF6 and ARF8 expression, and regulates both female and male reproduction. Development 133: 4211-4218. doi: 10.1242/ dev.02602

Yan K, Liu P, Wu C-A, Yang G-D, Xu R, Guo Q-H, Huang J-G, Zheng C-C (2012) Stress-induced alternative splicing provides a mechanism for the regulation of microRNA processing in Arabidopsis thaliana. Mol Cell 48: 521-531. doi: 10.1016/j.molcel.2012.08.032

Yang L, Liu Z, Lu F, Dong A, Huang H (2006) SERRATE is a novel nuclear regulator in primary microRNA processing in Arabidopsis. Plant J 47: 841-850. doi: 10.1111/j.1365-313X.2006.02835.x

Yang Z, Ebright YW, Yu B, Chen X (2006) HEN1 recognizes 21-24 nt small RNA duplexes and deposits a methyl group onto the 20 $\mathrm{OH}$ of the 30 terminal nucleotide. Nucleic Acids Res 34: 667-675. doi: 10.1093/nar/gkj474

Yu B, Bi L, Zheng B, Ji L, Chevalier D, Agarwal M, Ramachandran V, Li W, Lagrange T, Walker JC, Chen X (2008) The FHA domain proteins DAWDLE in Arabidopsis and SNIP1 in humans act in small RNA biogenesis. Proc Natl Acad Sci USA 105: 1007310078. doi: $10.1073 /$ pnas.0804218105

Yu B, Yang Z, Li J, Minakhina S, Yang M, Padgett RW, Steward R, Chen X (2005) Methylation as a crucial step in plant microRNA biogenesis. Science 307: 932-935. doi: 10.1126/science.1107130

Zadoks JC, Chang TT, Konzak CF (1974) A decimal code for the growth stages of cereals. Weed Res 14: 415-421. doi: 10.1111/j.13653180.1974.tb01084.x

Zhang J, Xu Y, Huan Q, Chong K (2009) Deep sequencing of Brachypodium small RNAs at the global genome level identifies microRNAs involved in cold stress response. BMC Genomics 10: 449. doi: 10.1186/1471-2164-10-449

Zhang W, Gao S, Zhou X, Xia J, Chellappan P, Zhou X, Zhang X, Jin $H$ (2010) Multiple distinct small RNAs originate from the same microRNA precursors. Genome Biol 11: R81. doi: 10.1186/gb-201011-8-r81

Zhang X, Zou Z, Gong P, Zhang J, ZiafK, Li H, Xiao F, Ye Z (2011) Over-expression of microRNA169 confers enhanced drought tolerance to tomato. Biotechnol Lett 33: 403-409. doi: 10.1007/s10529010-0436-0

Zhao B, Ge L, Liang R, Li W, Ruan K, Lin H, Jin Y (2009) Members of miR-169 family are induced by high salinity and transiently inhibit the NF-YA transcription factor. BMC Mol Biol 10: 29. doi: 10.1186/1471-2199-10-29

Zhao X, Zhang H, Li L (2013) Identification and analysis of the proximal promoters of microRNA genes in Arabidopsis. Genomics 101: 187-194. doi: 10.1016/j.ygeno.2012.12.004

Zhao Y, Zhang C, Liu W, Gao W, Liu C, Song G, Li WX, Mao L, Chen B, Xu Y, Li X, Xie C (2016) An alternative strategy for targeted gene replacement in plants using a dual-sgRNA/Cas9 design. Sci Rep 6: 23890. doi: 10.1038/srep23890

Zielezinski A, Dolata J, Alaba S, Kruszka K, Pacak A, Swida-Barteczka A, Knop K, Stepien A, Bielewicz D, Pietrykowska H, Sierocka I, Sobkowiak L, Lakomiak A, Jarmolowski A, Szweykowska-Kulinska Z, Karlowski WM (2015) mirEX 2.0 - an integrated environment for expression profiling of plant microRNAs. BMC Plant Biol 15: 144. doi: 10.1186/s12870-015-0533-2 